\title{
Wind Stress Curl over the Black Sea under Different Wind Regimes
}

\author{
M. V. Shokurov, I. G. Shokurova* \\ Marine Hydrophysical Institute, Russian Academy of Sciences, Sevastopol, Russian Federation \\ *e-mail: igshokurova@mail.ru
}

\begin{abstract}
Dependence of the magnitude and spatial distribution of wind stress curl in the Black Sea on the direction of the airflow prevailing over the sea surface are analyzed based on the data set of wind at $10 \mathrm{~m}$ height ERA-Interim reanalysis of European Centre for Medium-Range Weather Forecasts for the period 1979-2015 with a spatial resolution of $0.75^{\circ} \times 0.75^{\circ}$ and a temporal resolution of $6 \mathrm{~h}$. It is revealed that the average sea wind stress curl is cyclonic at the time of the north-western, northern and north-eastern winds throughout the year, and anticyclonic - during the south-western and western winds. On average, the north-eastern and northern winds are the most frequent for the year, the lowest - the southern and south-eastern winds. Taking into account the frequency of the wind, the greatest contribution to the creation of cyclonic wind stress curl are made by the situations with the northeastern wind, anticyclonic - with the western wind. Change of wind direction is accompanied by a change in the position of areas with cyclonic and anticyclonic vorticity. As a result, the wind of each direction creates a field of wind stress curl with its characteristic features that do not depend on the season. The manifestation of these features in the fields of seasonal cycle depends on the frequency of the winds direction.
\end{abstract}

Keywords: the Black Sea, wind direction, frequency of the wind direction, wind stress curl.

DOI: 10.22449/1573-160X-2017-6-12-23

(c) 2017, M. V. Shokurov, I. G. Shokurova*

(C) 2017, Physical Oceanography

\section{Introduction}

Wind and buoyancy flux on the sea surface are the main factors determining the large-scale circulation intensity the Black Sea [1-3]. Wind effect on the sea surface leads to the formation of wind currents. Spatial inhomogeneity in the wind field is accompanied by the occurrence of the Ekman vertical velocity, the change of the sea surface elevation and the formation of gradient currents. Wind curl is a quantitative feature of the wind field spatial inhomogeneity; therefore, an analysis of the annual and interannual variability of the magnitude of the wind curl is important for understanding the reasons of the large-scale circulation and vertical exchange variability in the sea.

Physical mechanisms that determine the wind curl and its seasonal variability were analyzed in $[2,4]$. It is shown that, in addition to the background curl created by large-scale medium atmosphere circulation, there are additional sources associated with thermal and dynamic orographic effects due to mountains $[4,5]$ and also a monsoon effect caused by seasonal changes of temperature contrasts between the sea and the surrounding land $[2,4,6]$. The monsoon effect has a significant influence on seasonal wind curl fluctuations [2, 4]. In winter, the positive difference between the heat fluxes to the atmosphere from the sea and the surrounding land generates a cyclonic (positive) wind curl as a result of convergence in the atmospheric boundary layer $[2,4]$. In summer, the situation is reverse - the negative dif- 
ference between heat fluxes generates an anticyclonic (negative) curl. On average, the dynamic orographic effect is predominant in the formation of the wind curl per the year [4].

Quantitative estimates of the seasonal variability of wind stress curl (WSC) in the Black Sea according to various reanalysis data, as well as its spatial distribution analysis, were carried out in [4, 7-11]. Estimates of the WSC magnitude and its distribution features differ depending on the spatial resolution of the reanalysis. According to all the estimates, on average the positive wind curl prevails over the Black Sea for a year, which supports the cyclonic nature of large-scale circulation in the sea along with other external effects (river runoff and heat fluxes).

Dependence of the sea mean wind curl on its direction according to the the average monthly data on the wind of the ERA-40 European Weather-Forecasts (ECMWF) reanalysis was considered in [12]. In this study applying the Self Organizing Maps algorithm, six characteristic typical wind fields over the sea were identified. Selection of the prevailing wind direction over the sea and the typification, in accordance with this direction, of synoptic situations of large-scale atmospheric circulation were carried out in [13].

The present paper is aimed to analyze the role of the direction of prevailing over the sea surface airflow in the formation of the magnitude and spatial distribution of wind stress curl. It is assumed that the flow direction is due to the distribution of the atmospheric pressure formed as a result of the joint action of all the aforementioned mechanisms. For the purpose at hand, the prevailing wind direction is identified and its comparison with the WSC magnitude and distribution, fixed for a given direction, is carried out. Along with the mean WSC created by wind of a certain direction, the WSC is considered taking into account the wind frequency the accumulated WSC calculated by summing over the number of situations with a certain wind direction. Sign and magnitude of the accumulated WSC characterize the contribution of the wind of each direction to the creation of a vertical velocity at the lower boundary of the Ekman layer.

\section{Data and their processing methods}

Wind at 10m height of ERA-Interim reanalysis of European Centre for MediumRange Weather Forecasts for the period 1979-2015 (38 years) with a spatial resolution of $0.75^{\circ} \times 0.75^{\circ}$ and a temporal resolution of 4-times daily (54056 time points) [14] are used.

For each time point according to the data, falling on the sea area (Fig. 1), the wind stress, its curl and the prevailing direction were calculated. The WSC was calculated using the aerodynamic formula $\tau=\rho_{a} C_{d}|\mathbf{V}| \mathbf{V}\left(\mathrm{N} / \mathrm{m}^{2}\right)$, where $\rho_{a}$ is the air density $\left(\mathrm{kg} / \mathrm{m}^{3}\right) ; C_{d}=1.3 \cdot 10^{-3}$ is the dimensionless drag coefficient; $\mathbf{V}=(u, v)$ is the wind velocity $(\mathrm{m} / \mathrm{s})$. WSC

$$
\operatorname{rot}_{z} \tau=\partial \tau_{y} / \partial x-\partial \tau_{x} / \partial y\left(\mathrm{~N} / \mathrm{m}^{3}\right)
$$

was calculated at the grid nodes being the centers of squares. There were the initial data on the wind at their vertices (Fig. 1). 


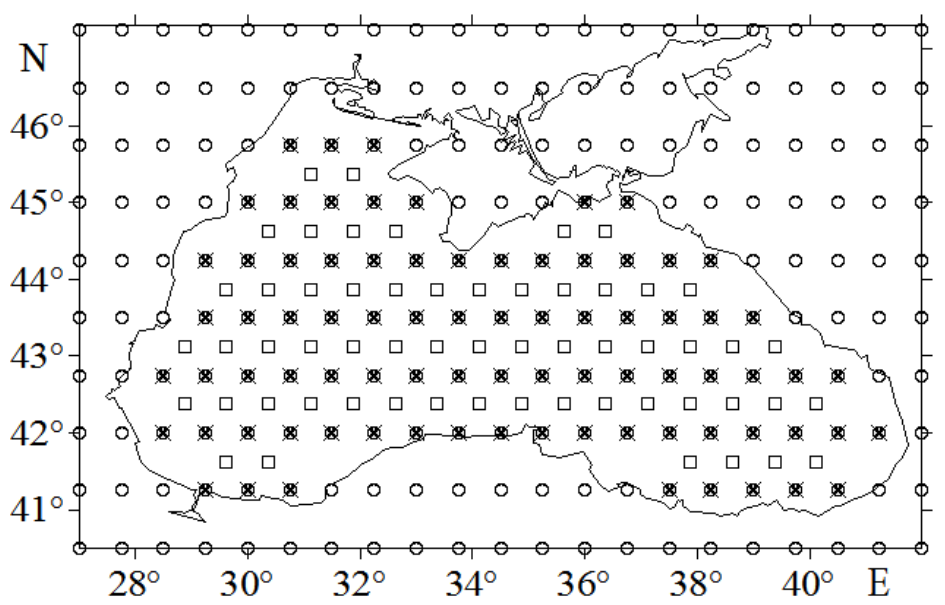

Fig. 1. Location of grid nodes: with wind velocity data $-\circ$, in the sea area $-\times$, with calculated curl values $-\square$

The prevailing over the sea area wind direction was determined for each time point (4-times daily) by averaging the velocity vector components $\mathbf{V}=(u, v)$ according to the sea area. The direction obtained was tied to one of the main geographical directions $\varphi(\varphi=1, \ldots, 8)$ : northern $(\mathrm{N})$, northeastern (NE), eastern (E), southeastern (SE), southern (S), southwestern (SW), western (W) and northwestern (NW). Thus, for each time point the WSC field was aligned with the prevailing wind direction corresponded to it.

The wind stress curl depending on the prevailing wind direction, taking into account the seasonal variability, was calculated as follows. Set of the WSC fields of all the time points $N(N=54056)$ was divided into groups (composites) corresponding to each of the wind directions $\varphi$ for each month $m(m=1, \ldots, 12)$. The number of time points in each group is $N_{\varphi, m}\left(N=\sum_{\varphi, m} N_{\varphi, m}\right)$.

For each group in the grid nodes, the following values were calculated:

- mean over the number of $N_{\varphi, m}$ time points WSC

$$
\operatorname{rot}_{z} \tau(\varphi, m)=\overline{\operatorname{rot}}_{z} \tau_{\varphi, m}\left(\mathrm{~N} / \mathrm{m}^{3}\right),
$$

- summarized over the number of $N_{\varphi, m}$ time points accumulated WSC

$$
\left(\operatorname{rot}_{z} \tau(\varphi, m)\right)_{A}=T \sum_{N_{\varphi, m}} \operatorname{rot}_{z} \tau\left(\mathrm{N} \cdot \mathrm{s} / \mathrm{m}^{3}\right),
$$

where $T$ (s) is an interval between the time points (6 hours). Further on the fields obtained, the mean values for the water area were calculated.

When calculating the WSC depending on the wind direction without taking into account the seasonal variation, set of the WSC fields of the periods was divided into 8 groups corresponding to each direction of the wind $\varphi$. The number of terms in each group is $N_{\varphi}\left(N=\sum_{\varphi} N_{\varphi}\right)$. For these groups in each grid nodes the mean 
over the number of time points WSC $-\operatorname{rot}_{z} \tau(\varphi)$ and summarized over the number of time points accumulated WSC - $\left(\operatorname{rot}_{z} \tau(\varphi)\right)_{A}$ were calculated.

The values of the wind velocity module depending on its direction, $V(\varphi, m)$ and $V(\varphi)$, were calculated in the similar way.

Mean monthly WSC $\operatorname{rot}_{z} \tau(m)$ and wind velocity module $V(m)$ values were calculated averaging over the number of the time points $N_{m}\left(N=\sum_{m} N_{m}\right)$, corresponding to each month $m$.

Frequency $P(\varphi)$ of the wind of each direction $\varphi$ was calculated as a percentage of the total number of the time points. On average, the wind frequency for a year was determined as $P(\varphi)=N_{\varphi} 100 / N$, per month as $P(\varphi, m)=N_{\varphi, m} 100 / N_{m}$.

Dependence of the spatial distribution of the WSC on the prevailing wind direction was analyzed on the basis of combining groups (composites) with a specific wind direction for winter (December - February) and summer (June - August).

\section{Results}

Sea area mean wind stress curl. Seasonal variation of the sea area mean wind stress curl $\operatorname{rot}_{z} \boldsymbol{\tau}(m)$ (Fig. 2, $a$ ) is characterized by the cyclonic curl intensification in winter with a peak in February $\left(3.6 \cdot 10^{-8} \mathrm{~N} / \mathrm{m}^{3}\right)$, weakening in spring and a change of curl to the anticyclonic one in summer in one month - June $\left(-0.5 \cdot 10^{-8} \mathrm{~N} / \mathrm{m}^{3}\right)$. In May and July, the WSC values are close to zero, but have a positive sign. On average, cyclonic vorticity predominates per year $\left(1.6 \times 10^{-8} \mathrm{~N} / \mathrm{m}^{3}\right)$.

It can be noted that in calculations according to data with a higher spatial resolution $[9,11]$ than in the present paper, the sea area mean curl is positive during the year, according to data with a lower resolution, the WSC is negative during the summer $[8,10]$.

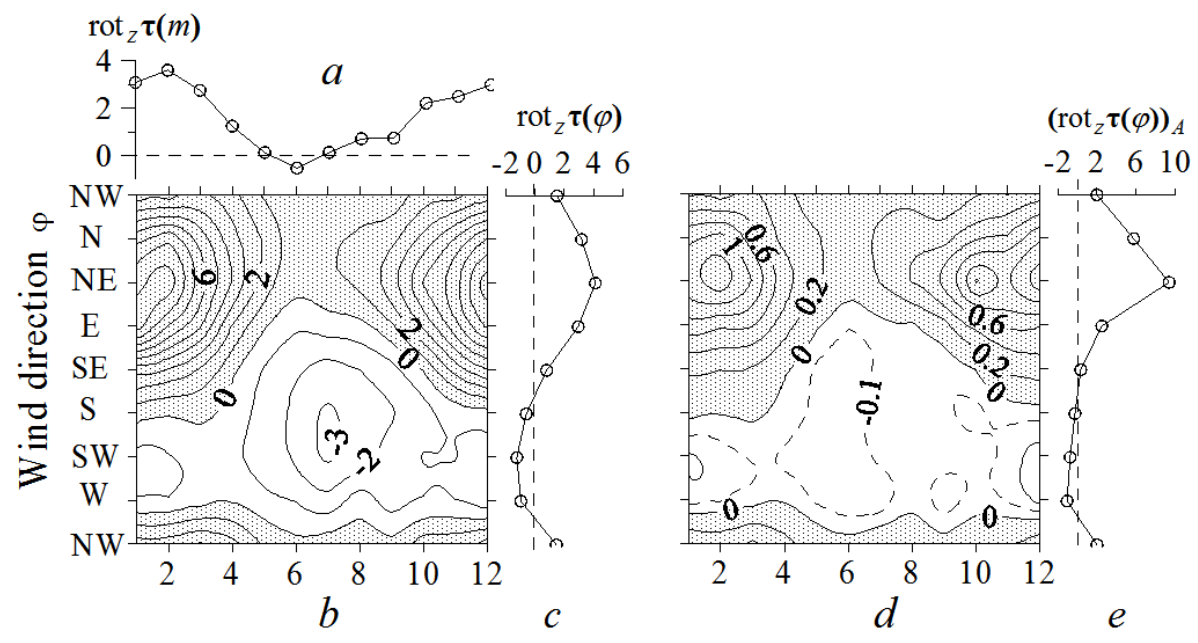

Fig. 2. The seasonal variation of the sea area mean wind stress curl, $\times 10^{-8} \mathrm{~N} / \mathrm{m}^{3},(a)$; variation of the wind stress curl, $\times 10^{-8} \mathrm{~N} / \mathrm{m}^{3},(b, c)$ and the accumulated wind stress curl, $\mathrm{N} \cdot \mathrm{s} / \mathrm{m}^{3},(d, e)$ by month $(b$, $d)$ and on average per year $(c, e)$ depending on the wind direction 
The diagram with the WSC $\operatorname{rot}_{Z} \tau(\varphi, m)$ values depending on the wind direction by months is shown in Fig. 2, $b$. Under the north, northeastern and northwestern winds, the WSC is cyclonic throughout a year; under the northeastern wind the highest values are observed. The maximum values of the cyclonic curl $\left(9.6 \cdot 10^{-8} \mathrm{~N} / \mathrm{m}^{3}\right)$ are observed under the northeastern wind in February and under the eastern - in January.

Under the western and southwestern winds the WSC is anticyclonic throughout a year (Fig. 2, $b$ ). The corresponding maximum negative values in absolute terms are observed in the southwestern and southern winds in July $\left(-3.2 \cdot 10^{-8} \mathrm{~N} / \mathrm{m}^{3}\right)$. Under the eastern, southeastern and southern winds, the WSC changes its sign depending on the season: in winter it is cyclonic, in summer - anticyclonic.

Dependence of the WSC $\operatorname{rot}_{z} \tau(\varphi)$ on the wind direction undivided into seasons is shown in Fig. 2, c. On average, per the year under the northwestern, northern, northeastern, eastern and southeastern winds, the sea area mean wind stress curl has a positive sign and is cyclonic; under the southern, southwestern and western winds, it is negative (anticyclonic). On average, per the year the maximum positive WSC is achieved under the northeastern wind $\left(4.1 \cdot 10^{-8} \mathrm{~N} / \mathrm{m}^{3}\right)$, the maximum negative WSC in absolute terms - under the southwestern wind $\left(-1.2 \cdot 10^{-8} \mathrm{~N} / \mathrm{m}^{3}\right)$.

Frequency of the wind direction prevailing over the sea. Monthly distribution of wind frequency $P(\varphi, m)$ is as follows (Fig. 3, $a)$. In December and January the southwestern and western winds have the highest frequency and in February and March - the northeastern ones. In this period the southeastern wind has the lowest frequency. In April almost all winds are equal in frequency. In May the situation is similar, but the frequency of northeastern and western winds increases. From June to October the frequency of winds with the southern component significantly decreases and is less than $10 \%$. In June the frequency of western, northwestern and northern winds increases. Winds with the northern component have the high frequency from July to September. In July and August, the frequency of the northern wind is $30 \%$ on average, and of the northeastern - more than $30 \%$ in August. In October and November the northeastern wind has the greatest frequency.

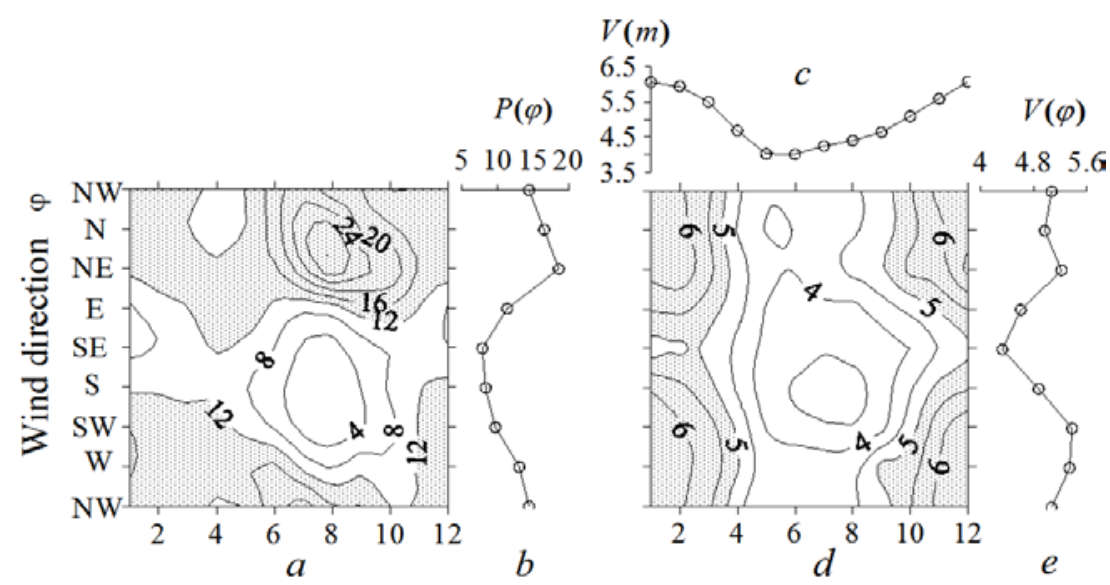

Fig. 3. Wind direction frequency (\%) by months $-a$ and on average per year $-b$; seasonal variability of the wind velocity $(\mathrm{m} / \mathrm{s})-c$ and its variation by month $-d$ and on average per year $-e$ depending on the wind direction 
On average per year (Fig. 3, b) the northeastern wind (18.6 \%) has the highest frequency $P(\varphi)$, the northern wind holds the second position (16.6\%). The southern and southeastern winds possess the lowest frequency (7.9 and $8.3 \%$, respectively). These indicators are in good agreement with the studies $[13,15]$.

Sea area mean accumulated wind stress curl. The accumulated WSC value is calculated by summing over the number of situations with a certain wind direction. Thus, the wind frequency in each direction is taken into account.

Comparison of the diagrams for the mean $\operatorname{rot}_{z} \tau(\varphi, m)$ (Fig. 2, $b$ ) and accumulated $\left(\operatorname{rot}_{z} \tau(\varphi, m)\right)_{A}$ (Fig. 2, $d$ ) curls shows that taking into account the wind frequency specifies the contribution of each direction to the curl development in the sea. The low frequency of the southern and southwestern winds in July and August is accompanied by their lower contribution to the accumulated anticyclonic curl, despite the fact that in these months, under the winds of these directions, a significant anticyclonic curl is created on average (Fig. 2, b). Therefore, in the seasonal variability (Fig. 2,a), the negative curl value is observed only in June.

Dependence of the accumulated WSC $\left(\operatorname{rot}_{z} \tau(\varphi)\right)_{A}$ on the wind direction on average per year is shown in Fig. 2, e. High repeatability of the northeastern wind during the year (Fig. 3, $b$ ) leads to the fact that its contribution to the cyclonic curl development in the Black Sea significantly exceeds the contribution of the northern and eastern winds and is the principal one. On average per year the southwestern wind creates the highest anticyclonic curl (Fig. 2, c), but due to the greater frequency of the western wind, it creates the largest accumulated anticyclonic curl (Fig. 2,e).

Wind velocity module. The curl value is also closely related to the wind velocity value, since under strong winds the velocity shift due to the spatial inhomogeneity of the wind increases. In the Black Sea due to its small size, the change in the surface (the wind is stronger over the sea than over the land) and orographic effects near the shore, the shift value increases.

In the seasonal cycle, wind intensification is observed in winter with a maximum in January $(6 \mathrm{~m} / \mathrm{s})$, a decrease - in summer with a minimum in June $(4 \mathrm{~m} / \mathrm{s})$ (Fig. 3, c). The mean wind velocity in the sea area, depending on its direction by month $V(\varphi, m)$ (Fig. 3, $d$ ) and the average per year $V(\varphi)$ (Fig. 3, $e$ ) is as follows.

On average per the year the highest velocity is achieved under the northeastern, western and southwestern winds (Fig. 3,e). Note that under the mentioned winds, a maximum cyclonic (the northeastern wind) and anticyclonic (the western and southwestern wind) curl is developed. Velocity of the southern, southeastern and eastern winds is less than the velocity of winds of other directions (Fig. 3, $e$ ). This seems to be related to a velocity weakening or a change in the wind direction near the coast due to orographic effects caused by the presence of high, long mountains on the eastern (the Caucasus Mountains) and southern (the Pontic Mountains) coasts of the Black Sea. The southeastern wind has minimum velocity on average PHYSICAL OCEANOGRAPHY ISS. 6 (2017) 
per year. This wind has also the lowest velocity during the year, except summer, when all winds with the southern component have low velocity (Fig. 3, $d$ ).

Seasonal variability of wind stress curl spatial distribution. In winters months (December - February) almost all the Black Sea water area is covered by a zone with the cyclonic curl (Fig. 4). High values of more than $8 \cdot 10^{-8} \mathrm{~N} / \mathrm{m}^{3}$ are recorded in the eastern part of the sea, the values of more than $4 \cdot 10^{-8} \mathrm{~N} / \mathrm{m}^{3}-$ in its western part. In March - April period cyclonic curl prevails but its value decreases. From May to September the area of cyclonic curl zones decreases and the one of anicyclonic curl zones grows. Their location has the form of a quadrupole structure previously noted in [7]. In the northeastern and southwestern parts of the sea the cyclonic curl zones are located, in the northwestern and southeastern ones - anticyclonic curl zones. Since July, in the northeastern part of the sea and in the east of the Bosporus the areas with cyclonic curl values of more than $8 \cdot 10^{-8} \mathrm{~N} / \mathrm{m}^{3}$ have appeared. In autumn, the size of the entire zone with cyclonic curl increases. The size of the zones with anticyclonic curl decreases and they are located along the western sea coast and along the southern one in its south-eastern part.
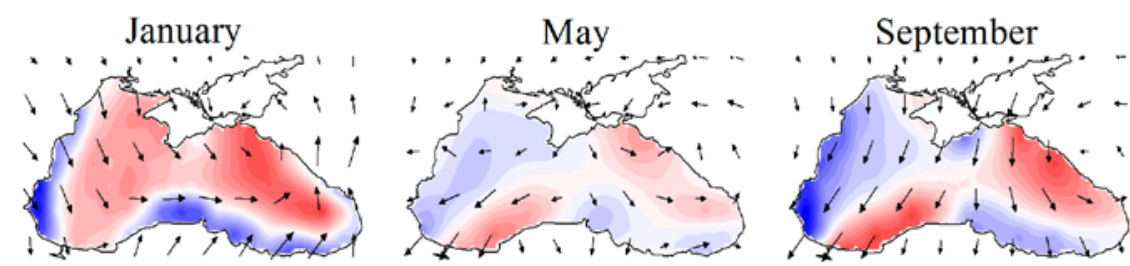

February

June

October
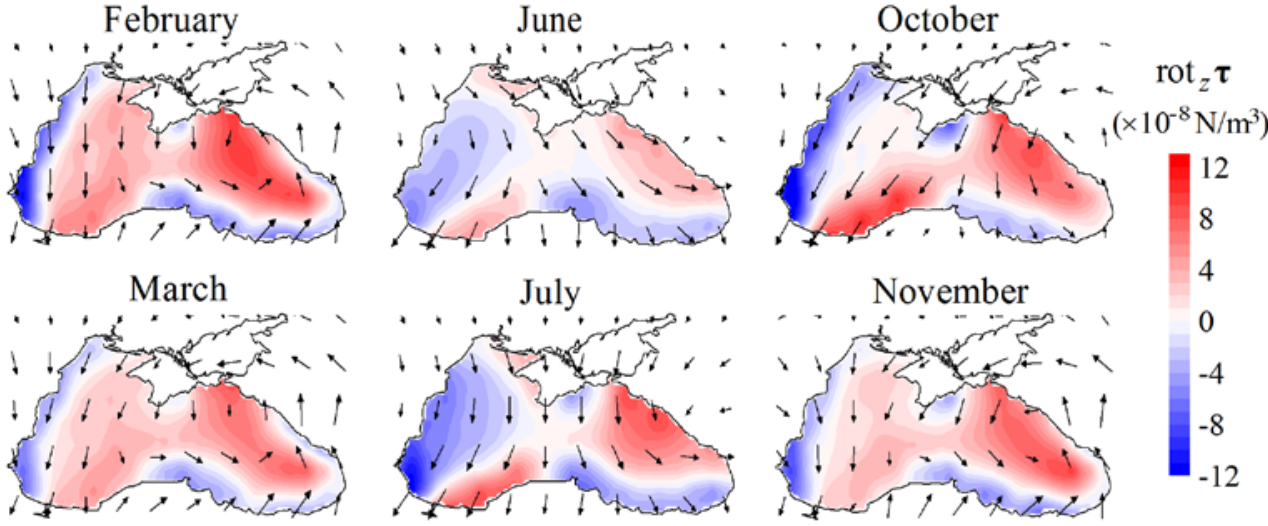

August

December
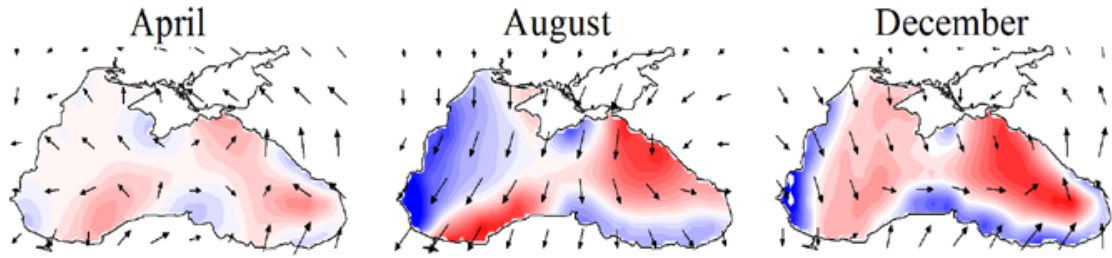

Fig. 4. Monthly mean wind stress curl fields 
It should be pointed out that wind stress curl spatial distribution calculated by the data of different reanalyses can significantly differ [8]. This is both due to the data spatial resolution and difference of physical process parameterizations in the atmospheric models by which the reanalysis is carried out. Moreover, the length of data series by the time can introduce changes in the spatial distribution details due to climatic changes of large-scale atmospheric circulation.

Spatial distribution obtained in the present work is close to the one from [8] calculated according to ECMWF reanalysis for $1979-1993$ period with $1.125^{\circ} \times 1.125^{\circ}$ spatial resolution [16]. A comparison with the distribution of high spatial resolution (25 km) obtained using HadRM3P model [9] and ERA-40 input data (1958-2001) with $\sim 125 \times 125 \mathrm{~km}$ resolution [17] shows the difference only in separate details.

Spatial distribution of wind stress curl at the winds of different directions. On the basis of averaging over the situations with a certain wind direction the fields of wind stress curl spatial distributions $\operatorname{rot}_{z} \tau(\varphi, m)$ were constructed (Fig. 5). Taking into account the annual course in the curl spatial distribution variability (Fig. 4), the fields were constructed individually for the winter season (according to combined data for December - February) and for the summer one (according to the data for June - August).

For each wind direction spatial distribution of the curl has a similar structure in both seasons: the positions of the sections with high values of cyclonic and anticyclonic curl coincide (Fig. 5). The difference consists in the fact that in summer the areas with cyclonic curl have smaller dimensions than in winter. And vice versa, in summer the areas with anticyclonic curl are bigger than the ones in winter. For example, in winter at northern, northeastern and eastern winds most of the water area is covered by the zone with cyclonic curl and in summer the area of this zone decreases (Fig. $5 a-c$ ). In summer at southern and southwestern winds almost all the water area is covered by the zone with anticyclonic curl (Fig. $5, e, f$ ).

When wind direction changes a spatial distribution of the curl also changes. If the wind direction changes to the opposite one, the positions of the areas with cyclonic and anticyclonic curls switch places. For instance, at northeastern wind the area with cyclonic curl covers the eastern, central and southern parts of the sea and the area with anticyclonic curl is located along the western and northwestern coasts (Fig. 5, b). At an opposite direction (southwestern wind) there is a reversed situation: the area with anticyclonic curl is located in the eastern, central and southern parts of the sea. The one with cyclonic curl is located along the western coast and in the northwestern shelf zone (Fig. 5, f). The same change of wind stress curl sign on the sea surface is observed for each wind while its direction changes to the opposite one.

The highest values of the cyclonic curl are recorded in winter at the synoptic situations with the northern and northeastern winds. The areas with high values are localized in the eastern part of the sea as well as along the Turkish coast, eastwards of the Bosphorus (Fig. 5, $a, b$ ). Anticyclonic curl high values are observed in winter at the western and southwestern winds along the Turkish coast (Fig. 5, $f, g$ ). 

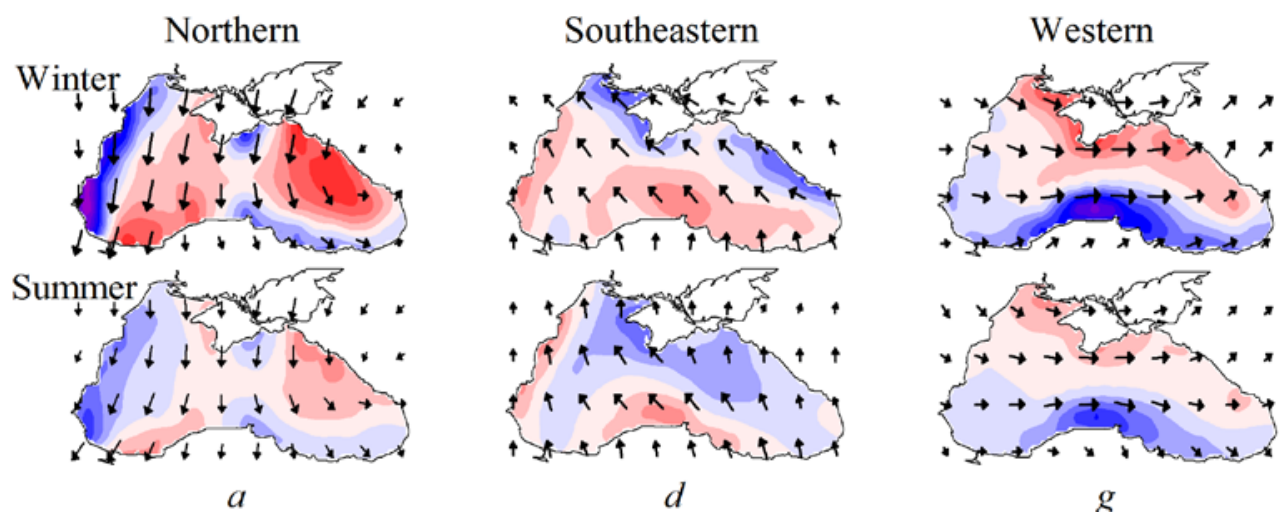

$a$

Southern

$g$
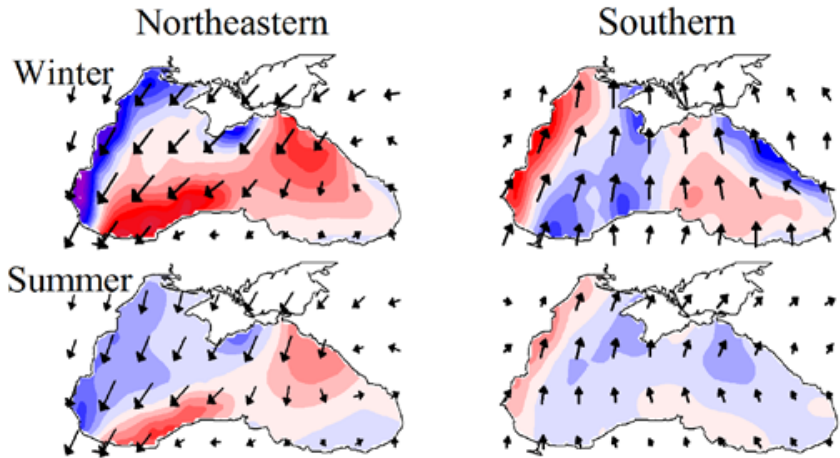

Northwestern
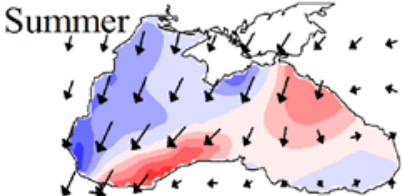

$b$

e

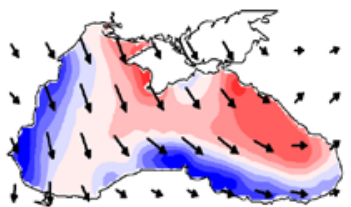

Eastern

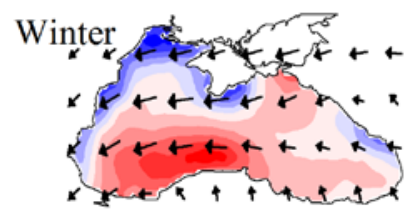

Southwestern
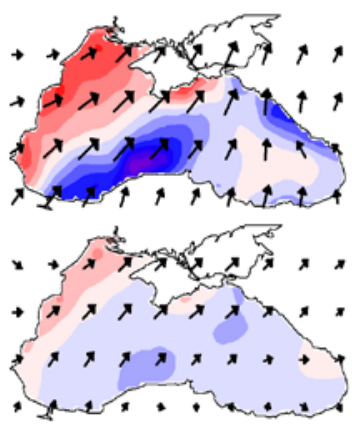

$9.0 \overrightarrow{(\mathrm{m} / \mathrm{s})}$

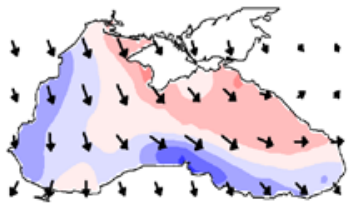

$h$

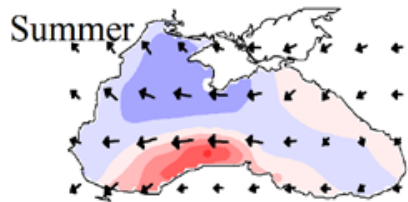

$f$

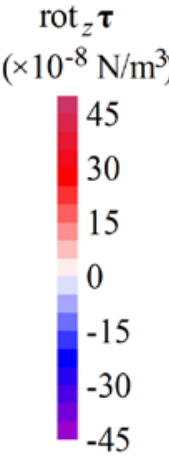

Fig. 5. Spatial distribution of wind stress curl $\operatorname{rot}_{Z} \tau\left(\times 10^{-8} \mathrm{~N} / \mathrm{m}^{3}\right)$ and wind velocity $V(\mathrm{~m} / \mathrm{s})$ depending on wind direction in the winter and summer

\section{Discussion}

The wind of each direction has a characteristic wind stress curl field on the sea surface (Fig. 5). WSC field structure is due to both a character of background large-scale atmospheric circulation and regional peculiarities such as sea area configuration and adjacent region terrain.

A typical synoptic situation of large-scale atmosphere circulation (background circulation) [13] corresponds to each wind flux predominating over the sea and 
selected by the basic geographical directions. Thus, for example, a northeastern wind predominating over the sea is due to such large-scale sea-level pressure field distribution at which northwards of the Black Sea an extensive anticyclone is located and southwards - a reduced atmospheric pressure [13]. For the southwestern wind there is a reversed distribution of atmospheric pressure. Thus, a change of predominating wind direction is a consequence of variation of large-scale synoptic situation.

Curl distribution and value are affected by regional peculiarities [4, 5, 9]. A change of the sea - land surface creates an additional velocity shift and intensifies the curl. Moreover, the presence of orographic effects near the shore has an impact on the curl value. Examples of this fact are high values of WSC along the Turkish coast with a mountainous terrain (the Pontic Mountains). It has a cyclonic character at northeastern and eastern winds and anticyclonic one at southwestern, western and north-western winds (Fig. 5, $b, c, f-h$ ). The presence of dynamic and orographic effects (when northern and northeastern winds flow around the Caucasus Mountains [4, 5, 9]) is accompanied by high values of cyclonic curl in the eastern part of the sea (Fig. $5 a, b$ ). Monsoon effect plays an important role in seasonal variability [2, 4].

The analysis of WSC distribution (Fig. 5) at synoptic situations with different wind direction and a regard to its frequency and velocity (Fig. 3) allow one to interpret some peculiarities of the curl distribution in a seasonal course (Fig. 4).

Seasonal curl fields are the result of averaging in the situations with different wind direction. Therefore, when calculating them an averaging of the curl with different sign takes place. This results in the fact that in the mean seasonal fields its values are small and do not exceed $\pm 11 \cdot 10^{-8} \mathrm{~N} / \mathrm{m}^{3}$ (Fig. 4) while the curl values generating by a wind of certain direction are rather high - up to $\pm 40 \cdot 10^{-8} \mathrm{~N} / \mathrm{m}^{3}$ (Fig. 5). But the highest frequency of the wind of a certain direction leads to the fact that peculiarities of the curl distribution (characteristic of the given direction) also manifest themselves in monthly average fields as areas with higher values of it.

The northeastern wind high frequency from July to October (Fig. 3, a) explains the existence of local areas with high cyclonic curl values $\left(>8 \cdot 10^{-8} \mathrm{~N} / \mathrm{m}^{3}\right)$ in the seasonal course fields located in the eastern part of the sea and along the southern coast eastwards of the Bosphorus (Fig. 4). Higher frequency of northeastern wind in February, in comparison with December and January (Fig. 3, a), is manifested in the fact that high curl values eastwards of the Bosphorus (Fig. 5, b) are recorded precisely in February (Fig. 4).

Anticyclonic curl high values generated by the western wind near the Turkish coast (Fig. 5, $b$ ) are most manifested in January when the frequency of this wind is higher in comparison with the one of the winds of other directions.

In April the frequency of the winds of all directions is practically equal (from $9.6 \%$ for the northern wind to $14.3 \%$ for the eastern one) (Fig. 3, a). This is accompanied by the absence of the areas with high cyclonic and anticyclonic WSC values in this month (Fig. 4).

In the eastern part of the sea a cyclonic curl conditioned by the northeastern wind (Fig. 5, $b$ ) which has high frequency during the entire year (Fig. 3, $a$ ) remains throughout the year (Fig. 4). 


\section{Conclusion}

Based on the selection of the prevailing wind direction for each 6-hour situation, the compilation of groups (composites) corresponding to each direction and the construction of mean fields for them the wind regime impact on the wind stress curl field peculiarities on the Black Sea was analyzed. It is found that the wind regime (wind direction, its frequency and speed) noticeably affects the wind stress curl value and plays an important role in the formation of its spatial distribution features.

At synoptic situations with prevailing northwestern, northern and northeastern winds the average WSC over the sea is cyclonic throughout the year, with the southwestern and western winds - anticyclonic. The situations with prevailing northeastern wind make the main contribution to cyclonic curl formation, the ones with western and southwestern winds - to anticyclonic.

WSC spatial distribution significantly depends on wind direction. At the wind of each direction a curl field with characteristic peculiarities remaining in all seasons is formed. Wind frequency makes a significant contribution to the formation of WSC spatial distribution in the seasonal course.

Acknowledgements. The research was carried out within the framework of State Order No. 0827-2015-0001 «Fundamental Research of the Processes in the Ocean - Atmosphere - Lithosphere System Determining Spatial-Temporal Variability of the Global and Regional Scale Environment and Climate».

\section{REFERENCES}

1. Stanev, E.V., 2005. Understanding Black Sea Dynamics: Overview of Recent Numerical Modeling. Oceanography, [e-journal] 18(2), pp. 56-75. doi:10.5670/oceanog.2005.42

2. Korotaev, G.K., 2001. O Prichine Sezonnogo Khoda Tsirkulyatsii Chernogo Morya [On a Reason of Seasonal Variation of the Black Sea Circulation]. Morskoy Gidrofizicheskiy Zhurnal, (6), pp. 14-20 (in Russian).

3. Kubryakov, A.A., Stanichny, S.V., Zatsepin, A.G. and Kremenetskiy, V.V., 2016. Long-term Variations of the Black Sea Dynamics and Their Impact on the Marine Ecosystem. J. Mar. Syst., [e-journal] 163, pp. 80-94. doi:10.1016/j.jmarsys.2016.06.006

4. Efimov, V.V., Shokurov, M.V. and Barabanov, V.S., 2002. Physical Mechanisms of Wind Circulation Forcing over the Inland Seas. Izv. Atmos. Ocean. Phys., 38(2), pp. 217-227.

5. Yarovaya, D.A. and Shokurov, M.V., 2012. Mezomasshtabnye Tsiklonicheskie Vikhri, Voznikayushchie nad Chernym Morem Vblizi Kavkazskogo Poberezh'ya [Mesoscale Cyclonic Vortices Generated over the Black Sea Near the Caucasian Coast]. Morskoy Gidrofizicheskiy Zhurnal, (3), pp. 14-30 (in Russian).

6. Grigoriev, A.V. and Petrenko, L.A., 1999. Chernoe More kak Faktor Vliyaniya na Atmosfernye Protsessy v Regione [Black Sea as a Factor of Influence on Atmospheric Processes in the Region]. In: V.A. Ivanov, ed., 1999. Ekologicheskaya Bezopasnost' Pribrezhnoy i Shel'fovoy Zon i Kompleksnoe Ispol'zovanie Resursov Shel'fa [Ecological Safety of Coastal and Shelf Zones and Comprehensive Use of Shelf Resources]. Sevastopol: MHI, pp. 17-26 (in Russian).

7. Zatsepin, A.G., Kremenetskiy, V.V., Poyarkov, S.G., Ratner, Yu.B. and Stanichny, S.V., 2002. Vliyanie Polya Vetra na Tsirkulyatsiyu Vod Chernogo Morya [Influence of Wind Field on Water Circulation in the Black Sea]. In: A.G. Zatsepin, M.V. Flint, eds., 2002. Kompleksnye Issledovaniya Severo-Vostochnoy Chasti Chernogo Morya [Multidisciplinary Investigations of the Northeast Part of the Black Sea]. Moscow: Nauka, pp. 91-105 (in Russian). 
8. Kara, A.B., Hurlburt, H.E., Wallcraft, A.J. and Bourassa, M.A., 2005. Black Sea Mixed Layer Sensitivity to Various Wind and Thermal Forcing Products on Climatological Time Scales. $J$. Climate, [e-journal] 18(24), pp. 5266-5293. doi:10.1175/JCLI3573R2.1

9. Efimov, V.V. and Anisimov, A.E., 2011. Climatic Parameters of Wind-field Variability in the Black Sea Region: Numerical Reanalysis of Regional Atmospheric Circulation. Izv. Atmos. Ocean. Phys., [e-journal] 47(3), pp 350-361. doi:10.1134/S0001433811030030

10. Polonsky, A.B. and Shokurova, I.G., 2011. Mnogoletnyaya Izmenchivost' Zavikhrennosti Kasatel'nogo Napryazheniya Treniya Vetra nad Chernym Morem po Dannym Reanaliza [Long-Term Variability of the Tangential Wind Stress Vorticity over the Black Sea from the Reanalysis Data]. In: V.A. Ivanov, ed., 2011. Ekologicheskaya Bezopasnost' Pribrezhnoy i Shel'fovoy Zon i Kompleksnoe Ispol'zovanie Resursov Shel'fa [Ecological Safety of Coastal and Shelf Zones and Comprehensive Use of Shelf Resources]. Sevastopol: MHI. Iss. 24, pp. 182-189 (in Russian).

11. Kubryakov, A.A. and Stanichny, S.V., 2015. Seasonal and Interannual Variability of the Black Sea Eddies and its Dependence on Characteristics of the Large-Scale Circulation. Deep-Sea Res. I., [e-journal] 97, pp. 80-91. doi:10.1016/j.dsr.2014.12.002

12. Capet, A., Barth, A., Beckers, J.-M. and Marilaure, G., 2012. Interannual Variability of Black Sea's Hydrodynamics and Connection to Atmospheric Patterns. Deep-Sea Res. II, [e-journal] 77-80, pp. 128-142. doi:10.1016/j.dsr2.2012.04.010

13. Chernyakova, A.P., 1965. Tipovye Polya Vetra Chernogo Morya [Typical Wind Fields of the Black Sea]. In: Sbornik Rabot Basseynovoy Gidrometeorologicheskoy Observatorii Chernogo i Azovskogo Morey [Collection of Works of the Basin Hydrometeorological Observatory of the Black and Azov Seas]. Leningrad: Gidrometeoizdat. Iss. 3, pp. 78-121 (in Russian).

14. Dee, D.P., Uppala, S.M., Simmons, A.J., Berrisford, P., Poli, P., Kobayashi, S., Andrae, U., Balmaseda, M.A., Balsamo, G. [et al.], 2011. The ERA-Interim Reanalysis: Configuration and Performance of the Data Assimilation System. Q. J. R. Meteorol. Soc., [e-journal] 137(656), pp. 553-597. doi:10.1002/qj.828

15. Simonov, A.I. and Altman, E.N. eds., 1991. Gidrometeorologiya i Gidrokhimiya Morey SSSR T. IV. Chernoe More. Vyp. 1. Gidrometeorologicheskie Usloviya [Hydrometeorology and Hydrochemistry of the USSR Seas. Vol. IV. Black Sea. Iss. 1. Hydrometeorological Conditions]. Leningrad: Gidrometeoizdat, 430 p. (in Russian).

16. Gibson, J.K., Kållberg, P., Uppala, S., Hernandez, A., Nomura, A. and Serrano, E., 1999. ERA-15 Description (version 2). ECMWF Re-Analysis Project Report Series. 1. UK: Reading, 74 p. Available at: https://www.ecmwf.int/en/elibrary/9584-era-description [Accessed: 17 October 2017].

17. Uppala, S.M., Kållberg, P.W., Simmons, A.J., Andrae, U., Bechtold, V.D.C., Fiorino, M., Gibson, J.K., Haseler, J., Hernandez, A. [et al.], 2005. The ERA-40 re-analysis. Q. J. R. Meteorol. Soc., [e-journal] 131(612), pp. 2961-3012. doi:10.1256/qj.04.176 